\title{
MODULAR PHASE CHANGE MATERIAL (PCM) THERMAL MANAGEMENT SYSTEMS FOR CYLINDRICAL LI-ION CELLS
}

\author{
Foo Shen Hwang ${ }^{*}$, Thomas Confrey ${ }^{1}$, Stephen Scully ${ }^{1}$, Dean Callaghan ${ }^{1}$, Cathal Nolan ${ }^{1}$, \\ Nigel Kent ${ }^{1}$, Barry Flannery ${ }^{2}$ \\ ${ }^{1}$ Department of Engineering, Institute of Technology Carlow, Ireland \\ ${ }^{2}$ Xerotech Limited, Ireland
}

\begin{abstract}
Sufficient thermal management is required for lithium-ion batteries to ensure prolonged battery life, optimal ionic reactions and to prevent thermal runaways. Thus, a majority of battery pack manufacturers utilize thermal management systems consisting of either air or coolant-based circuits to reduce the batteries operating temperature. However, such systems require active components including pumps and fans which increase operating costs. As such, phase change materials (PCM) based cooling systems are attractive alternatives due to the system's ability to dissipate heat passively and its high latent heat capacity. Nonetheless, there are several challenges in implementing such a system for commercial usage including the encapsulation of the PCM material, enhancement of the PCM's thermal conductivity and the optimal volume requirements of the system. With such requirements in mind, this paper introduces a modular honeycomb based PCM cooling system enhanced with aluminum fins. The modular aspect of the design involves both triangular slots and protrusions that allow the system to be attached to each other. Paraffin is used as the PCM material due to its non-corrosive nature and its similarity in melting point with the optimal operating temperature of the battery. Volume optimization of the system is parameterized through the computational fluid dynamics (CFD) software and its corresponding temperature reduction is observed. Results from the study display a significant temperature reduction in the batteries maximum temperature, however further experimentation is required to validate the accuracy of the results.
\end{abstract}

KEY WORDS: Phase Change Material (PCM), CFD, thermal management, macro-encapsulation

\section{INTRODUCTION}

There has been a steady increase in EV demand across the past few years. A recent statistic from Bloomberg New Energy Finance report predicted that up to 11 million EV's will be produced by 2025 with more production to follow in the next few years [1]. With such a rise, lithium ion battery (LIB) production would simultaneously follow suit. As such, there is a simultaneous need to improve LIB performance. From an environmental standpoint, better battery efficiencies would reduce the overall amount of rare earth materials mined such as cobalt to produce the battery [2]. While there are numeral parameters that could be improved across LIBs, enhancement in thermal regulatory systems would play a key role in prolonging battery life. Thermal issues that could affect LIBs include capacity fade, thermal runaway, current imbalance and low power performance [3]. The main challenge in implementing an effective thermal regulatory system in EVs though are the limited space, cost-effectiveness of the system and overall energy consumption of the system [4].

Phase change material (PCM) based thermal management systems could potentially be utilized as alternatives to conventional air and liquid cooling systems due to PCMs having high latent heat storage capacities. There are numeral PCM types used within industry, each with differing thermophysical properties. As such, the 
cooling requirements of the application should first be considered before determining the PCM type used. In regard to li-ion battery thermal management, paraffin bolsters several suitable qualities including excellent thermal and chemical stability, non-corrosivity, high latent heat capacities, and low costs [5]. Despite such beneficial traits, there are two major considerations that should be addressed when utilizing PCMs including thermal conductivity enhancement for PCMs generally have low thermal conductivities and the method of containment $[6,7]$. The container employed has to fulfill several requirements including preventing PCM spillage during the melting process, maintain sufficient heat transfer between the heat source and the PCM, and to provide sufficient void space to accommodate for PCM expansion during the melting process [7].

Several studies have been conducted on PCM thermal conductivity enhancement including micro and macro encapsulation, addition of additives with high thermal conductivities such as with graphite powder and introduction of metallic fins/tubing to increase the heat transfer area $[8,9,10,11,12]$. Encapsulation generally involves encapsulating a core material within a shell material to improve heat transfer efficiency and area, prevent environmental contamination towards the core material and improvement on material handling [13]. However, a majority of such encapsulation techniques are difficult to achieve and require additional specialized equipment to be produced [13]. It is often easier to utilize fins for they are cheaper, can be adapted towards most container shapes, allow for relatively great thermal contact and can be manufactured easily [11, $14,15]$. The effectiveness of the fins can be further enhanced with the addition of carbon nanoparticles [16]. As such the passive thermal management system constructed within this study focuses on adapting this design aspect.

\section{METHODOLOGY}

\subsection{Lithium-Ion Heat Generation Model}

The battery modelled within this study is based on the Panasonic NCR 18650B. Thermophysical properties of the battery are adapted from literature values and are tabulated as displayed within Table 1 while the other parameters of the battery are stated within Table $2[17,18]$.

Table 1 Battery thermophysical properties

\begin{tabular}{c|c}
\hline \hline Thermophysical properties & Battery \\
\hline$\rho\left(\mathrm{kg} / \mathrm{m}^{3}\right)$ & 2939 \\
\hline$c_{p}(\mathrm{~J} / \mathrm{kg} \mathrm{K})$ & 2400 \\
\hline$k(W / \mathrm{mK})$ & 3 \\
\hline \hline
\end{tabular}

Table 2 Battery parameters

\begin{tabular}{c|c|c|c}
\hline $\begin{array}{c}\text { Diameter } \\
(\mathrm{mm})\end{array}$ & $\begin{array}{c}\text { Length } \\
(\mathrm{mm})\end{array}$ & $\begin{array}{c}\text { Nominal } \\
\text { Voltage }(\mathrm{V})\end{array}$ & $\begin{array}{c}\text { Typical Capacity } \\
(\mathrm{m} . \mathrm{Ah})\end{array}$ \\
\hline 18 & 65.3 & 3.6 & 3350 \\
\hline \hline
\end{tabular}

The heat source of the battery is quantified through Bernardi's equation as highlighted within Eq. 1 below.

$$
Q=I\left[(O C V-V)-\left(T_{b a t} \frac{d O C V}{d T}\right)\right]
$$

Whereby the first group of values describes the irreversible Joule heating effects and the second the reversible entropic heat produced by the battery. Apart from the discharge current, the variables across Eq. (1) vary transiently depending on the state of charge (SOC) of the battery. 


\subsection{PCM thermophysical characteristics and modelling}

During the melting/solidification process of the PCM, four major sequences occur which are pure conduction, mixed conduction and natural convection, major natural convection and declining solids [19]. To simplify the modelling process of the PCM, the thermophysical properties are assumed to undergo pure conduction with piecewise linear thermophysical properties based on the transient temperature of the battery. Table 2 displays the paraffin thermophysical properties used within the model [20].

Table 2 Thermophysical properties of paraffin wax

\begin{tabular}{l|c}
\hline \multicolumn{1}{c|}{ Thermophysical properties } & Paraffin \\
\hline Melting temperatures $\left({ }^{\circ} \mathrm{C}\right)$ & $26-28$ \\
\hline Specific heat capacity $(\mathrm{J} / \mathrm{kg} \mathrm{K})$ & $1800-2400$ \\
\hline Specific latent Heat $(\mathrm{kJ} / \mathrm{kg})$ & 140 \\
\hline Solid density $\left(\mathrm{kg} / \mathrm{m}^{3}\right)$ & 870 \\
\hline Liquid density $\left(\mathrm{kg} / \mathrm{m}^{3}\right)$ & 750 \\
\hline Thermal Conductivity $(\mathrm{W} / \mathrm{mK})$ & $0.085-0.05$ \\
\hline \hline
\end{tabular}

It should be noted that the specific heat capacity, $c_{p}$ peaks during the transitional phase of the PCM. Figure 1 displays the transitional specific heat capacity incorporated within the model. A piecewise model was used to approximate the specific heat capacity of the paraffin used.

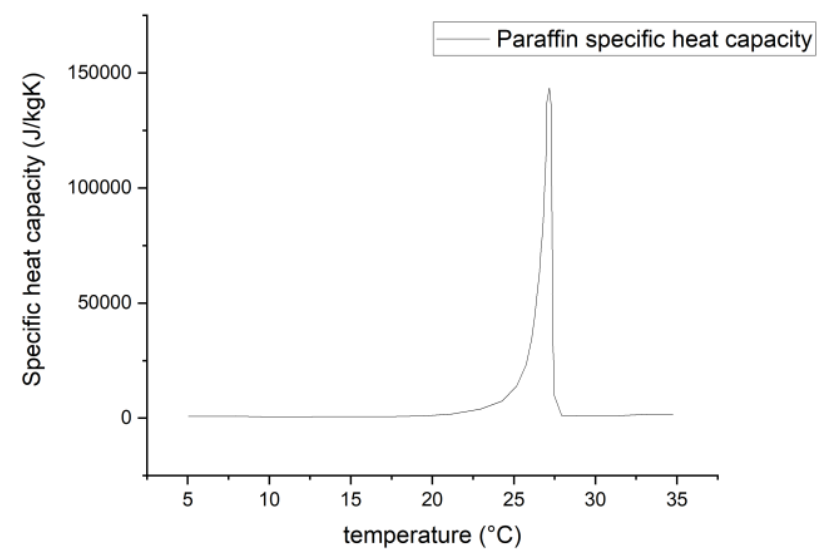

Fig 1 Piecewise linear model of paraffin specific heat capacity in relation to temperature [20, 21]

The latent heat storage capacity, $L$ of the paraffin can be calculated by integration of the $c_{p}$ function in respect to the transitional phase as highlighted within Eq. 2 [22]. $T_{1}$ and $T_{2}$ represent the melting range of the paraffin.

$$
\int_{T_{1}}^{T_{2}} c_{p}(T) d T=\Delta h_{T_{1} \rightarrow T_{2}} \approx L
$$

Thermal conductivity is heavily influenced by the frequency in which photons vibrate at [23]. As such, the thermal conductivity of the PCM drops significantly from the solid phase to the liquid phase due to mismatched 
photons, weak pairing within the atomic matrix and decreased uniformity across the photons [24]. Figure 2 displays the thermal conductivity drop of the paraffin modelled.

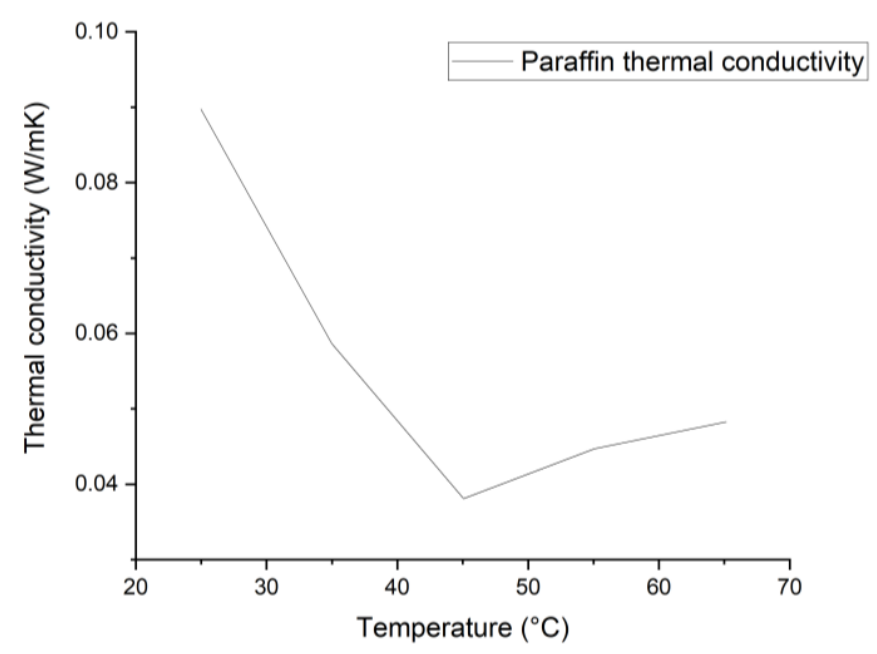

Fig 2 Paraffin thermal conductivity in relation to temperature [24]

\subsection{Design concept}

The design of the modular PCM thermal management system had to fulfil several criteria including the enhancement of the PCM's thermal conductivity, adequate space storage for the PCM, compactness and to be easily manufacturable. With such considerations in mind, a hexagonal model with inward fins was proposed as displayed within Fig. 3. The hexagonal shape allows the model to be packed without any loss in space volume while being able to house adequate quantities of paraffin within its channels. Aluminium was selected as the main housing material due to its high thermal conductivity and relatively economical cost. To maintain adequate thermal contact and to prevent a shorted circuit between the battery and the main aluminium housing, a thermal pad was considered to fill the gap. Several other parameters were considered in optimizing the thermal efficiency of the model. Alterations towards the fin's thickness was not considered for studies conducted by Al-Abidi et al. highlighted that an increase in fin thickness does not greatly affect the rate of heat transfer[25]. In addition, Al-Abidi et al. have also described that an increase in the number of fins would reduce the phase change gap [25]. Hence, the number of fins attached onto the model was also parameterised for its effectiveness in reducing the batteries maximum temperature.

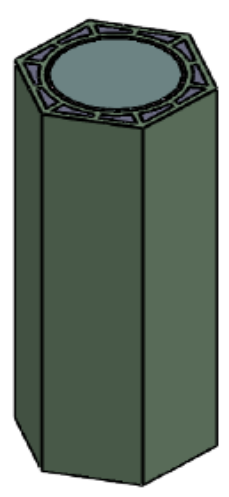

Isometric View

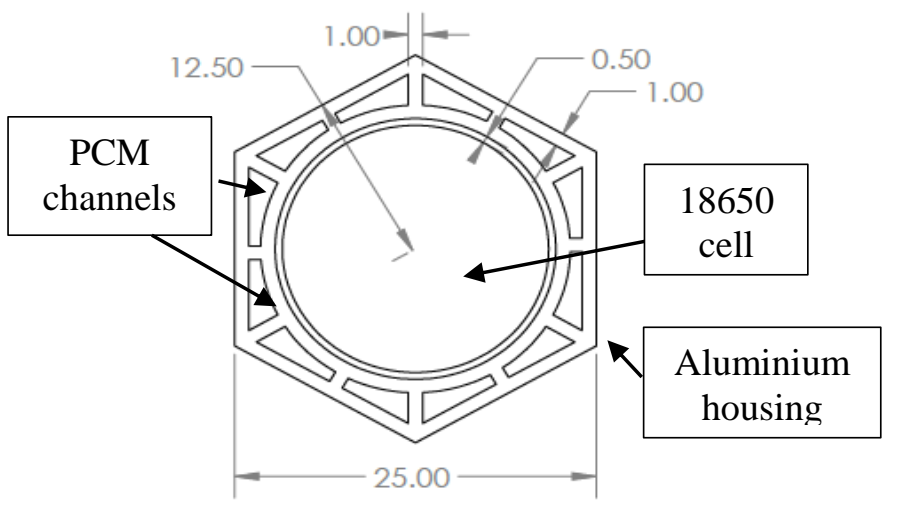

Top View

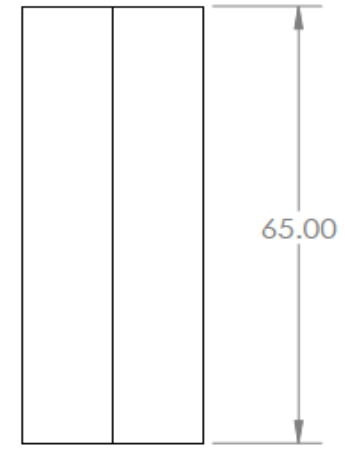

Side View

Fig 3 Concept design of the enhanced PCM passive thermal management system 
Subsequently, the fin length and PCM volume used was parameterized by increasing the model's width by 2 $\mathrm{mm}$ increments and its thermal dissipation effectiveness was observed. The range of model width's and PCM volume parameterized are tabulated within Table 3 .

Table 3 Parameterized values of the model

\begin{tabular}{c|c|c}
\hline \hline Model & Width length $(\mathrm{mm})$ & PCM Volume $\left(\mathrm{mm}^{3}\right)$ \\
\hline 1 & 25 & 5132.946 \\
\hline 2 & 27 & 9696.609 \\
\hline 3 & 29 & 14710.605 \\
\hline 4 & 31 & 20174.934 \\
\hline 5 & 33 & 26089.596 \\
\hline 6 & 35 & 32454.591 \\
\hline 7 & 37 & 39269.919 \\
\hline 8 & 39 & 46535.580 \\
\hline 9 & 41 & 54251.574 \\
\hline 10 & 43 & 62417.901 \\
\hline 11 & 45 & 71034.561 \\
\hline
\end{tabular}

\section{RESULTS AND DISCUSSION}

\subsection{Fin Length Parameterization}

The transient heat generation of the 18650 battery at a $1 \mathrm{C}$ discharge rate was modelled under natural convection and is compared with a battery discharged at the same rate with Model 1 of the PCM system within CFD. The heat transfer coefficient of both models was set at $10 \mathrm{~W} / \mathrm{m}^{2} \mathrm{~K}$ to mimic natural convection conditions. Results from the model as displayed within Fig. 4 indicate that the system does greatly reduce the overall maximum temperature of the battery as compared to a naturally convected system.

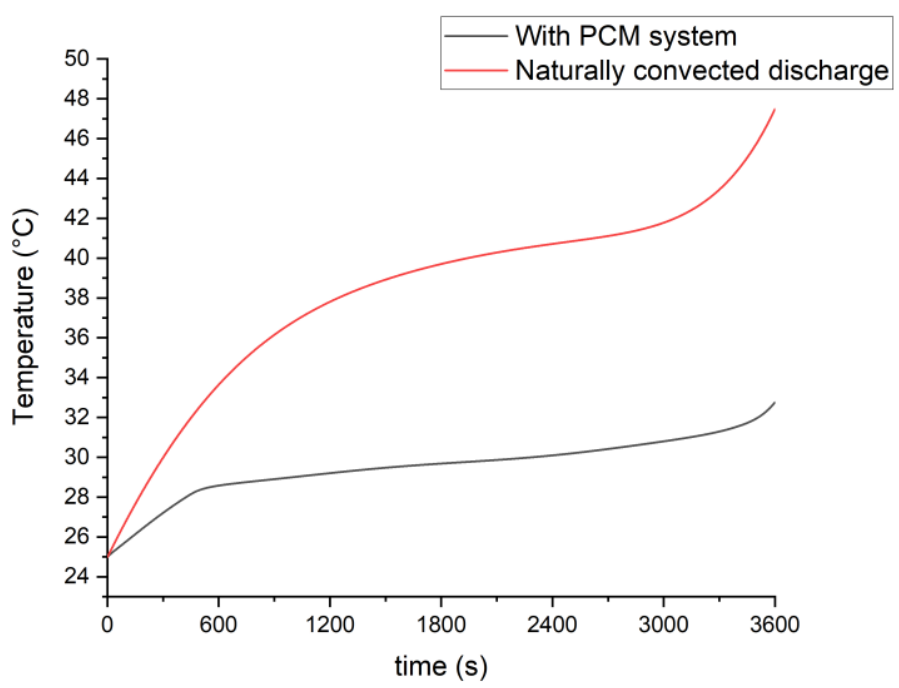

Fig 4 Comparison between naturally convected system and modelled PCM system 
To further explore the effectiveness of extending the fin length and the volume of PCM used, the remaining models were subjected to the heat generation of the battery at a $1 \mathrm{C}$ discharge rate and the batteries corresponding maximum temperature was observed as highlighted in Fig. 5

Model 1
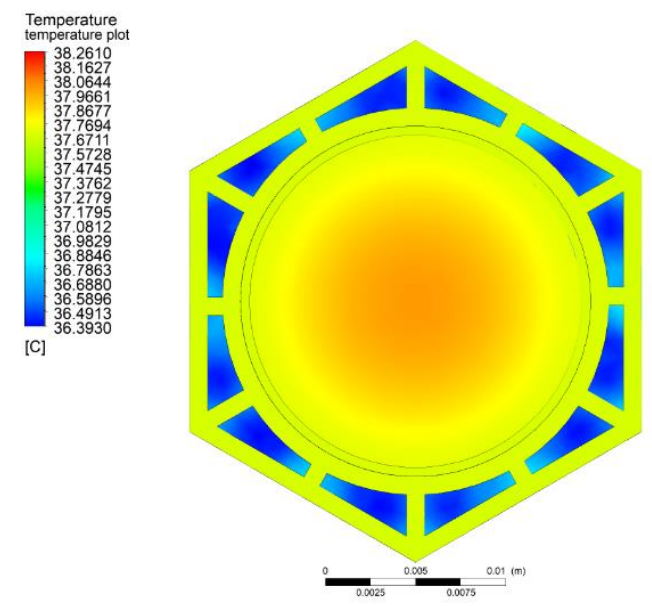

Model 3
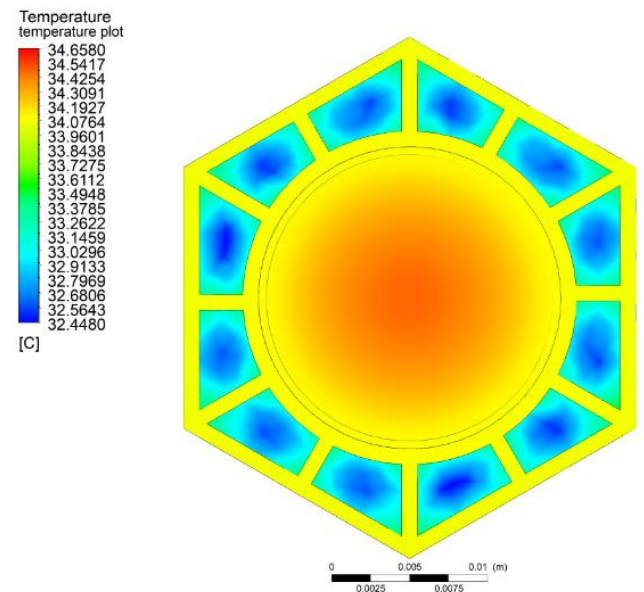

Model 9

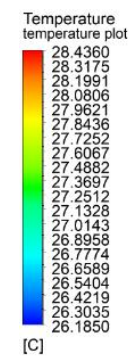

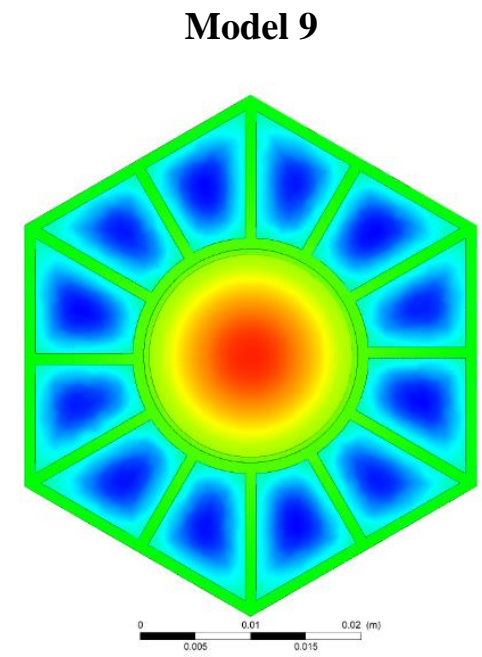
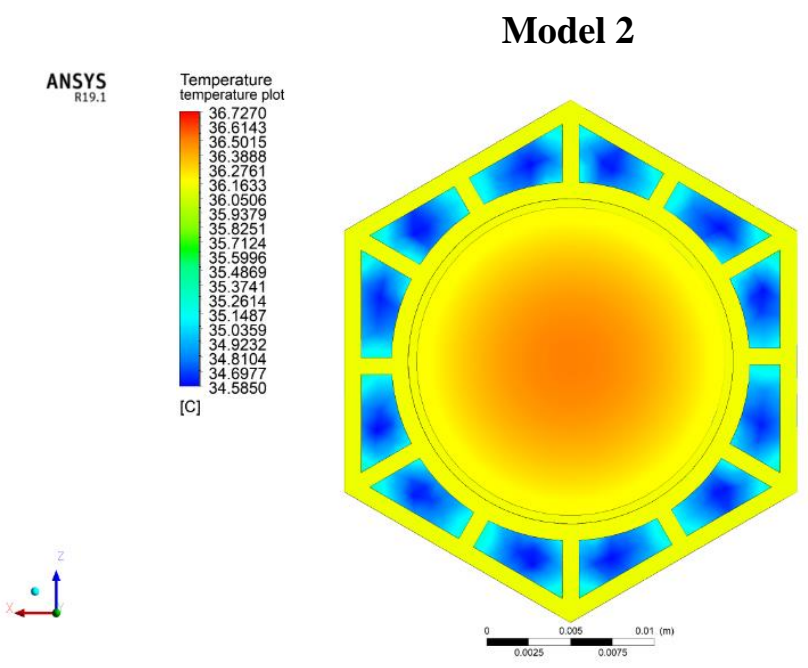

ANSYS

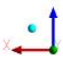

Model 5
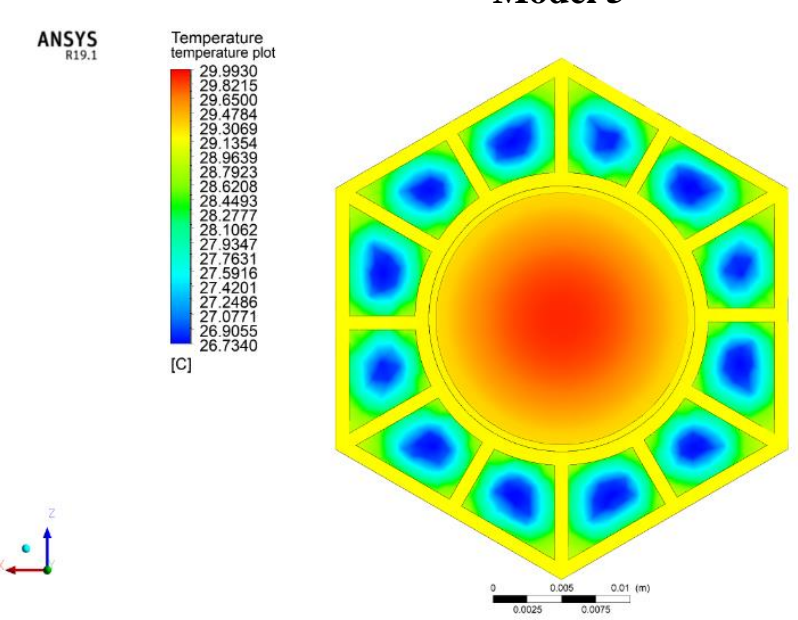

ANSYS

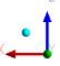

\section{Model 11}
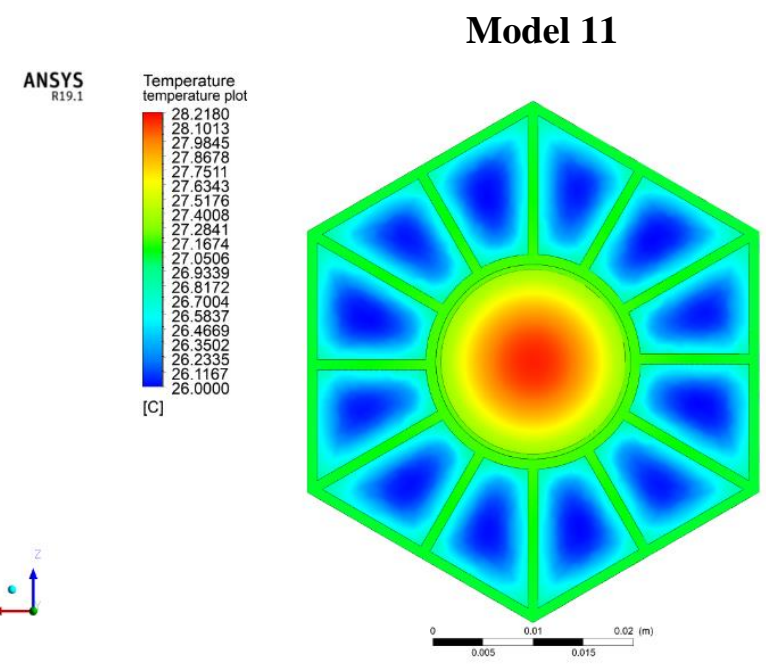

ANSYS

Fig 5 PCM volume parameterization at a battery discharge rate of $1 \mathrm{C}$ 
It was observed that the greater the width of the model and the volume of the PCM used, the lower the maximum core temperature of the battery. Fig. 6 displays the maximum temperature rise of the battery across the various model iterations. It was noted that the drop in the battery's maximum temperature is not as significant pass the $6^{\text {th }}$ model. As space is a premium within a battery pack, the $6^{\text {th }}$ model appears to be the most appropriate iteration to be used.

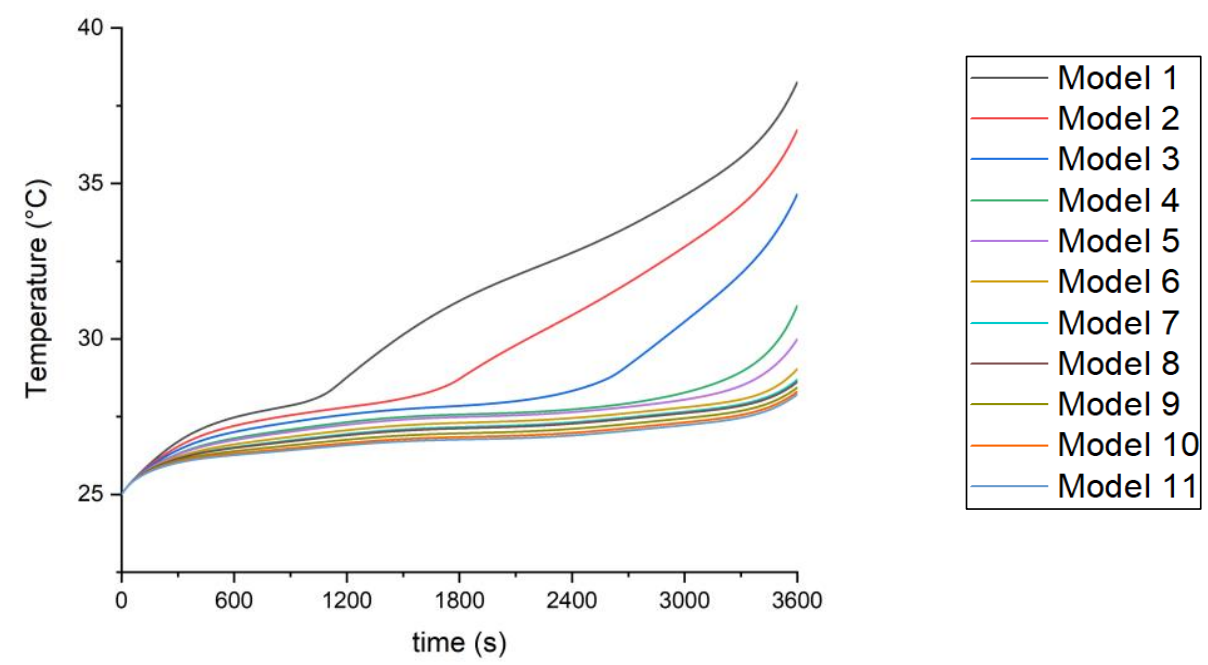

Fig 6 Temperature rise of the battery in response to the increasing the length of the fins

\subsection{Fin Number Parameterization}

With the ideal fin length determined in section 3.1, the number of fins within the geometry was parameterized as presented across Fig 7. To ensure even heat distribution across the paraffin, the fins are evenly spaced apart within the model.

The transient temperature rise of the batteries are then tabulated as displayed within Fig 8. Notably, the effects of increasing the number of fins was not as significant in lowering the maximum battery temperature as compared to increasing the fin length of the model. Furthermore, the temperature rise of the battery does not get lowered beyond 10 fins. As such, the ideal number of fins for the model is 10 as to reduce the weight of the system while maintaining adequate cooling. 


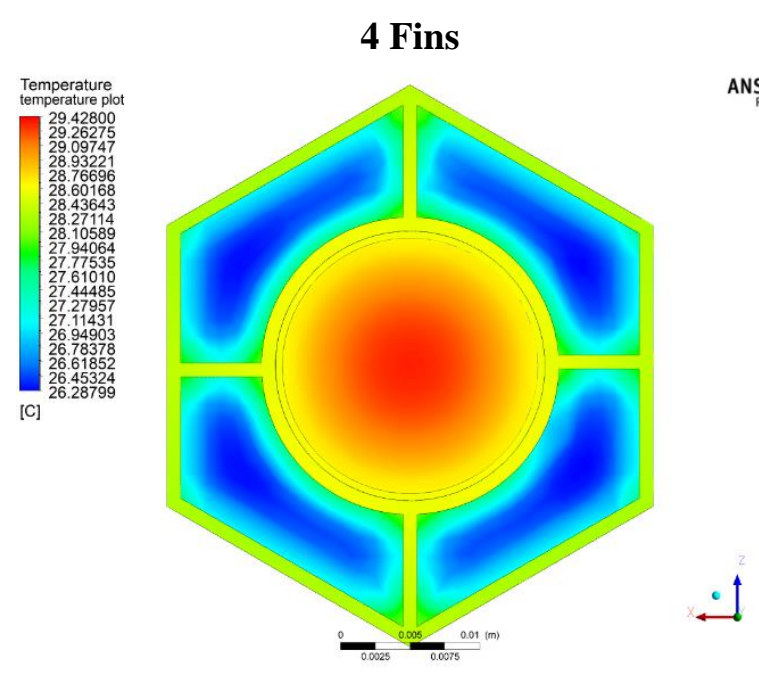

8 Fins

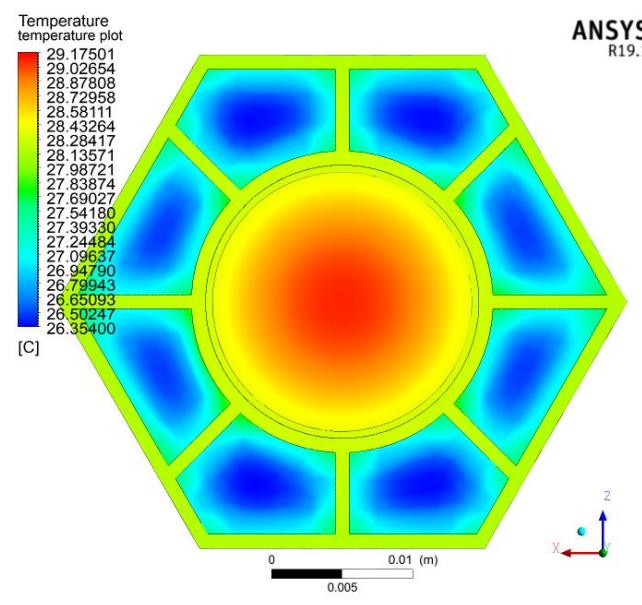

12 Fins
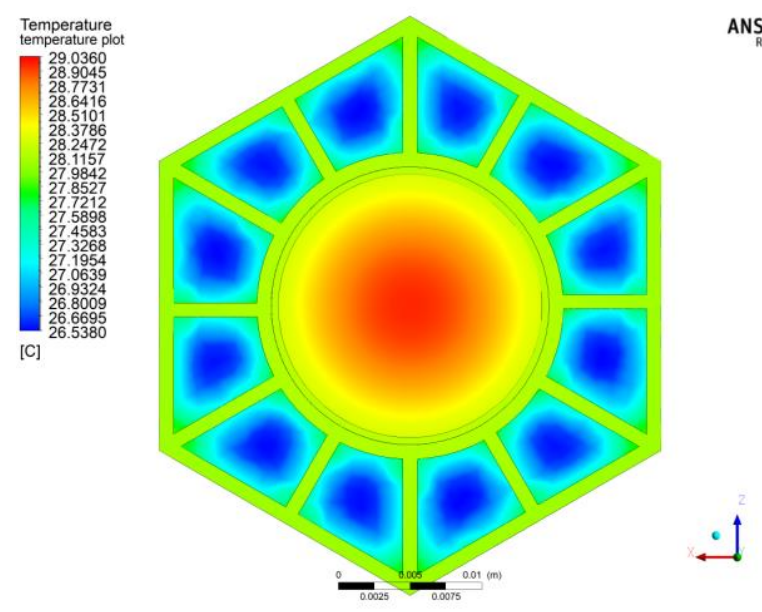

6 Fins
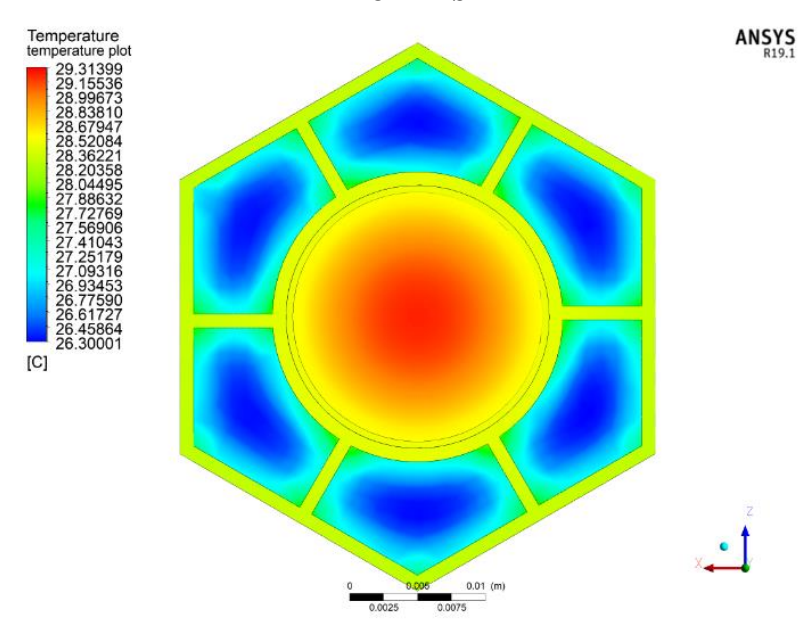

10 Fins

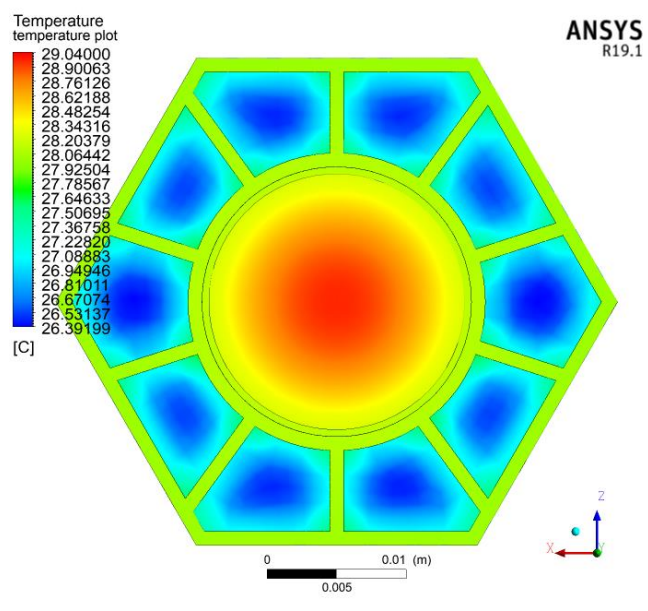

14 Fins

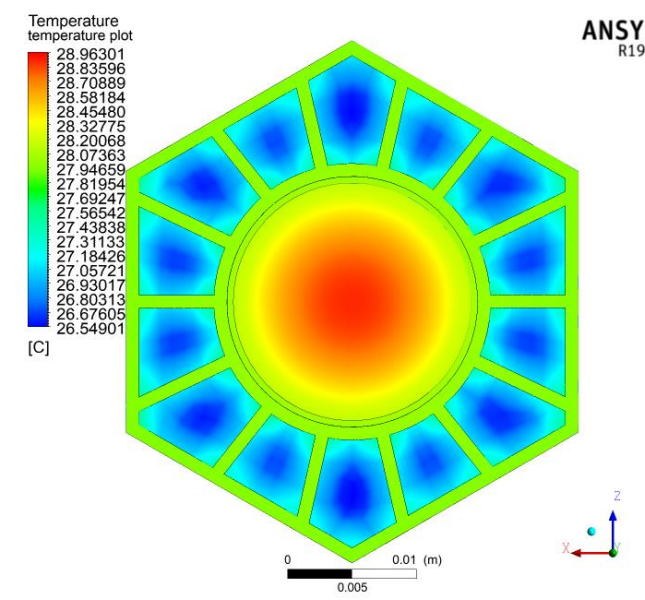

Fig 7 Fin parameterization 


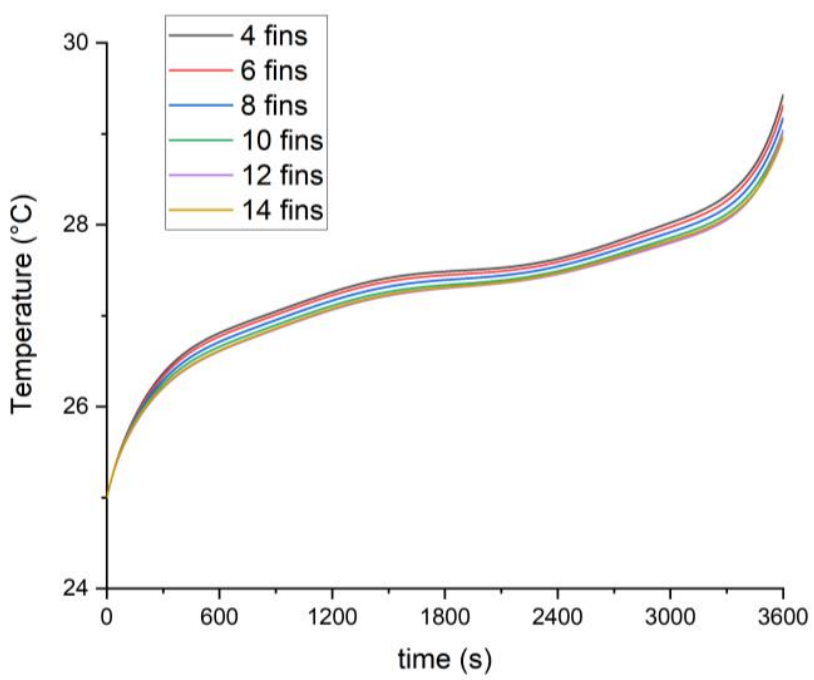

Fig 8 Temperature rise of the battery with respect to increasing the number of fins

\subsection{Comparison of the system with/without PCM}

The difference between the system with and without the PCM was also modelled to determine the effectiveness of the fins purely as a heatsink. Discharge parameters are set similarly to the conditions set in Section 3.1 and 3.2 with the batteries being discharged at a rate $1 \mathrm{C}$ under naturally convection. The maximum temperature rise of the battery is then tabulated as shown in Fig 10.

\section{Fins Only}

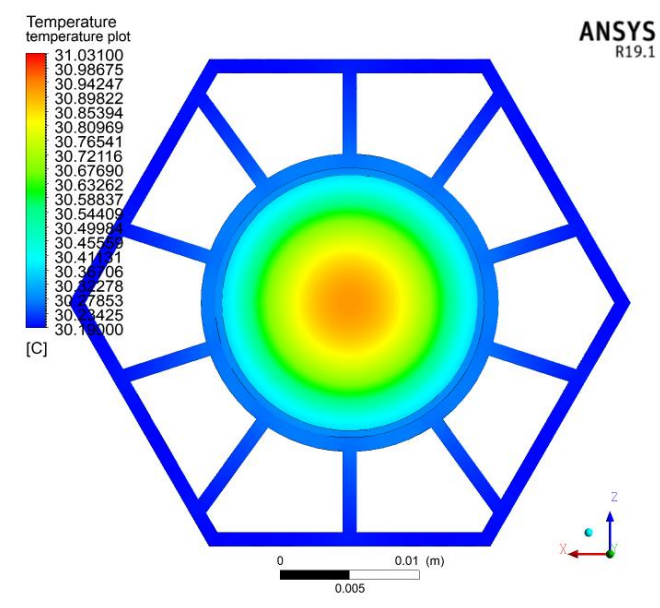

Fins and PCM

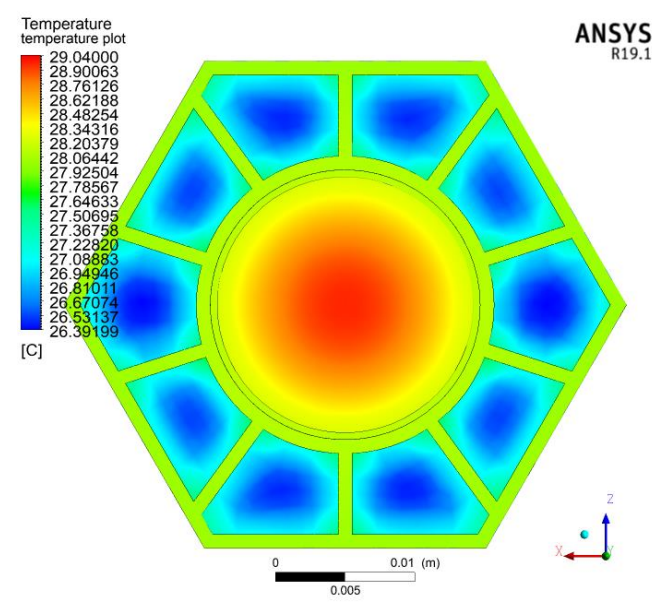

Fig 9 Comparison of the finned system with/without the PCM

As displayed across Fig 10, the presence of the PCM significantly lowers the battery's maximum temperature throughout the discharge phase. Moreover, the temperature rise of the PCM system was noted to be more uniformed throughout the discharge process which in turn could lead to higher discharge efficiencies for the PCM based system [26]. While the purely finned system may be lighter and does indeed lower the battery's maximum temperature rise, the addition of PCMs into the structure is far more effective in lowering the maximum temperature rise of the battery and stabilizing the battery's overall temperature. 


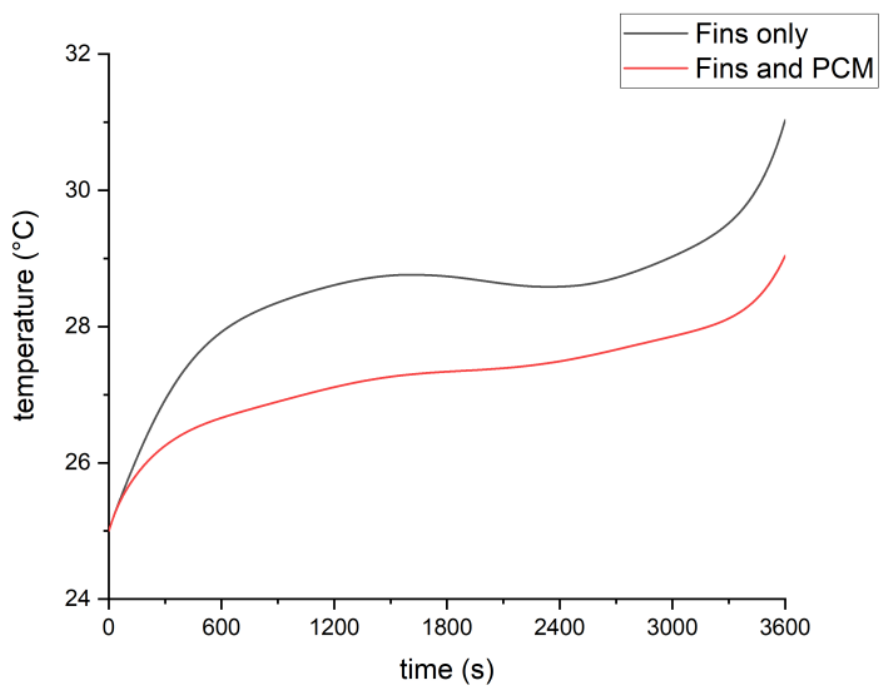

Fig 10 Temperature rise of the finned system with/without the PCM

\subsection{Varying ambient temperature}

The PCM based model is then modelled for varying ambient conditions as exhibited across Fig 11. As the melting point of the PCM incorporated is around $27^{\circ} \mathrm{C}$, the temperature rise of the system operating around such temperatures would be lower due to the increased amounts of energy required to overcome the high latent heat capacity of the paraffin used. Such conditions would be beneficial for the battery for it is able to maintain its optimal operating temperature of $15-35^{\circ} \mathrm{C}$. Nevertheless, the PCM based system is able to mitigate the temperature rise of the battery at higher ambient temperatures as well.
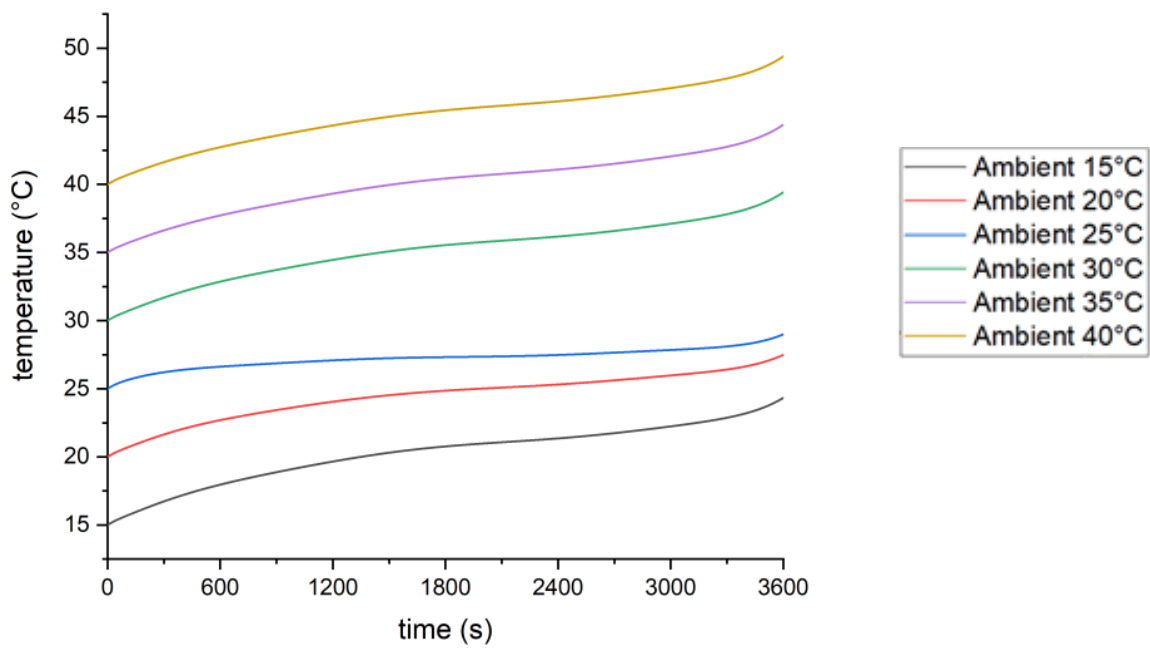

Fig 11 Temperature rise of the battery at varying ambient temperatures 


\subsection{Varying discharge rates}

Heat generation of higher discharge rates was applied onto the PCM model and its corresponding temperature rise of the battery was observed within Fig. 12. The maximum temperature rise of the battery at both the $1.5 \mathrm{C}$ and $2.0 \mathrm{C}$ discharge rate appears to be overall higher but is still within the optimal battery operating temperature of $15-35^{\circ} \mathrm{C}$.

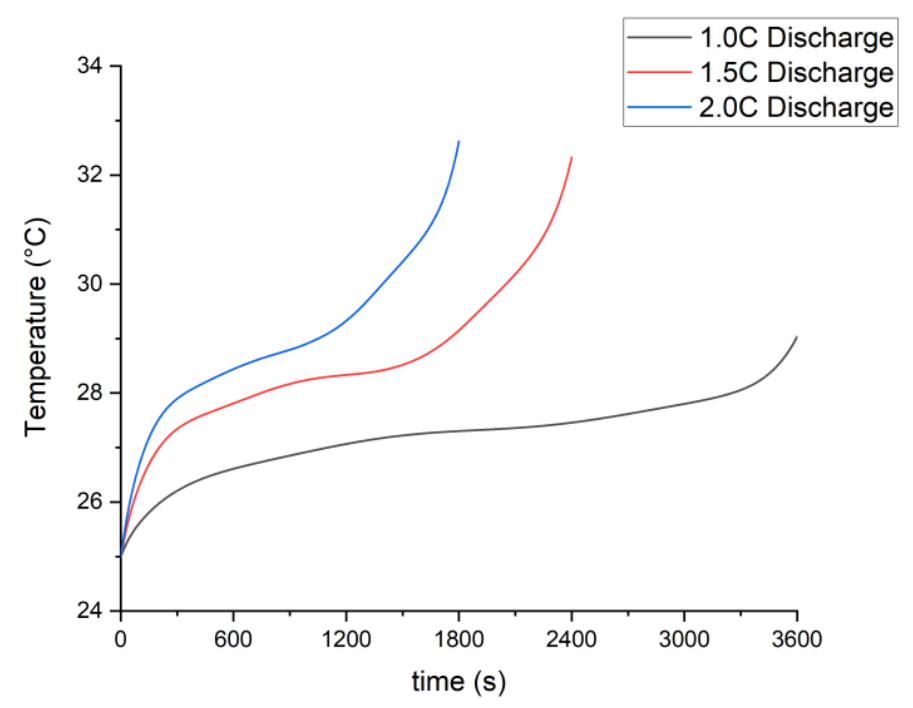

Fig 12 Temperature rise of the battery under 1.0, 1.5 and 2.0C discharge rate

\section{CONCLUSION AND FUTURE WORK}

With the objective of designing a modular passive thermal management system for a cylindrical lithium-ion battery, a hexagonal finned based heat sink enhanced with PCMs was utilized. From the parameterization studies conducted through the CFD program ANSYS, it was determined that the structure of $35 \mathrm{~mm}$ in width, using $32454.591 \mathrm{~mm}^{3}$ of paraffin with 10 fins is the most effective design in lowering the battery's overall maximum temperature. It should be acknowledged that the CFD study assumes perfect conduction throughout the model. Implementing sufficient thermal resistance across the model would increase the accuracy of the results however experimental data is required to determine adequate tolerances. Additionally, the thermophysical properties of the PCM was presumed to be piece wise-linear throughout the model. A more effective method in modelling the PCM would be to account for the liquid fraction variation as constructed by Joybari et.al. [11]. The effectiveness of the model could also be further improved with the addition of graphite nanoparticles and as such could be used for future iterations of the model. Further experimentation is required to determine the accuracy of the model's results. Works on building the model are being commenced at the moment and results will be updated across future iterations of the study.

\section{NOMENCLATURE}

$\begin{array}{llcllc}c_{p} & \text { specific heat capacity } & (\mathrm{J} / \mathrm{kg} \mathrm{K}) & \text { OCV } & \text { open circuit voltage } & (\mathrm{V}) \\ h & \text { enthalpy } & (\mathrm{J}) & \rho & \text { density } & \left(\mathrm{kg} / \mathrm{m}^{3}\right) \\ \mathrm{L} & \text { specific latent heat } & (\mathrm{kJ} / \mathrm{kg}) & \mathrm{Q} & \text { heat generation } & (\mathrm{W}) \\ I & \text { current } & (\mathrm{A}) & \mathrm{T} & \text { temperature } & \left({ }^{\circ} \mathrm{C}\right) \\ k & \text { thermal conductivity } & (\mathrm{W} / \mathrm{mK}) & V & \text { voltage } & (\mathrm{V})\end{array}$




\section{REFERENCES}

[1] "Electric Vehicle Outlook 2019 | Bloomberg New Energy Finance,” BloombergNEF. [Online]. Available: https://about.bnef.com/electric-vehicle-outlook/. [Accessed: 12-Sep-2019].

[2] G. Josh, "Electric Vehicles, Batteries, Cobalt, and Rare Earth Metals," Union of Concerned Scientists, 25-Oct-2017. [Online]. Available: https://blog.ucsusa.org/josh-goldman/electric-vehicles-batteries-cobalt-and-rare-earth-metals. [Accessed: 22-Nov2018].

[3] M. R. Khan, M. J. Swierczynski, and S. K. Kær, "Towards an Ultimate Battery Thermal Management System: A Review," Batteries, vol. 3, no. 1, p. 9, Mar. 2017.

[4] P. Ahmad, K. Matt, K. Gi-Heon, S. Shriram, and Kandler, "Tools for Designing Thermal Management of Batteries in Electric Drive Vehicles," 2013.

[5] S. Himran, A. Suwono, and G. A. Mansoori, "Characterization of Alkanes and Paraffin Waxes for Application as Phase Change Energy Storage Medium,” Energy Sources, vol. 16, pp. 117-128, Jan. 1994.

[6] T. E. Alam, J. S. Dhau, D. Y. Goswami, and E. Stefanakos, "Macroencapsulation and characterization of phase change materials for latent heat thermal energy storage systems," Appl. Energy, vol. 154, pp. 92-101, Sep. 2015.

[7] Advanced Cooling Technologies, "PCM Heat Sink Design Considerations," 2019. [Online]. Available: https://www.1act.com/innovations/thermal-storage/pcm-heat-sink-design-considerations/. [Accessed: 10-Jan-2019].

[8] F. Agyenim, N. Hewitt, P. Eames, and M. Smyth, "A review of materials, heat transfer and phase change problem formulation for latent heat thermal energy storage systems (LHTESS)," Renew. Sustain. Energy Rev., vol. 14, no. 2, pp. 615-628, Feb. 2010.

[9] K. Nithyanandam and R. Pitchumani, “Thermal energy storage with heat transfer augmentation using thermosyphons," Int. J. Heat Mass Transf., vol. 67, pp. 281-294, Dec. 2013.

[10] M. M. Farid, A. M. Khudhair, S. A. K. Razack, and S. Al-Hallaj, "A review on phase change energy storage: materials and applications," Energy Convers. Manag., vol. 45, no. 9, pp. 1597-1615, Jun. 2004.

[11] M. M. Joybari, F. Haghighat, S. Seddegh, and A. A. Al-Abidi, "Heat transfer enhancement of phase change materials by fins under simultaneous charging and discharging," Energy Convers. Manag., vol. 152, pp. 136-156, Nov. 2017.

[12] P. Mantilla Gilart, Á. Yedra Martínez, M. González Barriuso, and C. Manteca Martínez, "Development of PCM/carbon-based composite materials," Sol. Energy Mater. Sol. Cells, vol. 107, pp. 205-211, Dec. 2012.

[13] A. Hassan, M. Laghari, and Y. Rashid, "Micro-Encapsulated Phase Change Materials: A Review of Encapsulation, Safety and Thermal Characteristics," Sustainability, vol. 8, p. 1046, Oct. 2016.

[14] F. Agyenim, N. Hewitt, P. Eames, and M. Smyth, "A review of materials, heat transfer and phase change problem formulation for latent heat thermal energy storage systems (LHTESS)," Renew. Sustain. Energy Rev., vol. 14, no. 2, pp. 615-628, Feb. 2010.

[15] R. M. Abdel-Wahed, J. W. Ramsey, and E. M. Sparrow, "Photographic study of melting about an embedded horizontal heating cylinder," Int. J. Heat Mass Transf., vol. 22, no. 1, pp. 171-173, Jan. 1979.

[16] R. Singh, S. Sadeghi, and B. Shabani, "Thermal Conductivity Enhancement of Phase Change Materials for Low-Temperature Thermal Energy Storage Applications,” Energies, vol. 12, no. 1, p. 75, Jan. 2019.

[17] S. Al Hallaj, H. Maleki, J. S. Hong, and J. R. Selman, "Thermal modeling and design considerations of lithium-ion batteries," J. Power Sources, vol. 83, no. 1, pp. 1-8, Oct. 1999.

[18] E. Gümüşsu, Ö. Ekici, and M. Köksal, "3-D CFD modeling and experimental testing of thermal behavior of a Li-Ion battery," Appl. Therm. Eng., vol. 120, pp. 484-495, Jun. 2017.

[19] B. J. Jones, D. Sun, S. Krishnan, and S. V. Garimella, "Experimental and numerical study of melting in a cylinder," Int. J. Heat Mass Transf., vol. 49, no. 15, pp. 2724-2738, Jul. 2006.

[20] C. M, C. Giuseppina, V. Lo Brano, A. Marvuglia, and A. Orioli, "A Photovoltaic panel coupled with a phase changing material heat storage system in hot climates," 2008, pp. 1-13.

[21] I. Medved", A. Trník, and L. Vozár, "Modeling of a heat capacity peak and an enthalpy jump for a paraffin-based phase-change material," 2016.

[22] S. N. Al-Saadi and Z. (John) Zhai, "Systematic evaluation of mathematical methods and numerical schemes for modeling PCMenhanced building enclosure," Energy Build., vol. 92, pp. 374-388, Apr. 2015.

[23] T. Luo and J. R. Lloyd, "Non-equilibrium molecular dynamics study of thermal energy transport in Au-SAM-Au junctions," Int. J. Heat Mass Transf., vol. 53, no. 1, pp. 1-11, Jan. 2010.

[24] M. Chaichan, K. H, and A.-A. M, "Thermal Conductivity Enhancement by using Nano-material in Phase Change Material for Latent Heat Thermal Energy Storage Systems,” SAUSSUREA, vol. 5, pp. 48-55, Aug. 2015.

[25] A. A. Al-Abidi, S. Mat, K. Sopian, M. Y. Sulaiman, and A. Th. Mohammad, "Internal and external fin heat transfer enhancement technique for latent heat thermal energy storage in triplex tube heat exchangers," Appl. Therm. Eng., vol. 53, no. 1, pp. 147-156, Apr. 2013.

[26] D. D. Agwu, F. Opara, N. Chukwuchekwa, D. Dike, and L. Uzoechi, "Review Of Comparative Battery Energy Storage Systems (Bess) For Energy Storage Applications In Tropical Enviroments,” Sep. 2018. 